Revista de Estudios Histórico-Jurídicos

[Sección Historia del Pensamiento Político]

XXXV (Valparaíso, Chile, 2013)

[pp. 783 - 797]

\title{
"TRANSLATIO IMPERII". Del MAR DE DANTE AL OCÉANO DE VÁZQUEZ de MENCHACA
}

[“Translatio Imperii” from Dante's Sea to Vasquez de Menchaca's Ocean]

\author{
FABIO VÉLEZ*
}

Universidad Autónoma de Madrid, España

\begin{abstract}
RESUMEN
Este artículo trata de perseguir los efectos (y argumentos) de una translation imperii que se tiene que enfrentar a la inclusión de nuevos elementos geográficos; de ahí el subtítulo: del mar de Dante al océano de Vázquez de Menchaca. No se pretende, pues, abarcar toda la historia jurídica de este concepto, como sí de desentrañar algunos hitos relevantes por lo que a su legitimidad se refiere.
\end{abstract}

\section{Palabras Clave}

Translatio imperii - Mar - Océano Imperio -Propiedad - Transferencia.

\section{Abstract}

This article is aimed at pursuing the effects (and arguments) of a translation imperii that has to face the inclusion of new geographical elements; hence the subtitle: from Dante's sea to Vázquez de Menchaca's ocean. It does not attempt to cover all the legal history of this concept, but intends to unravel some relevant milestones regarding its legitimacy.

\section{KEYWORDS}

Translatio imperii - Sea - Ocean Empire-Property - Transference.

RECIBIDO el 23 de mayo y ACEPTADO el 19 de julio de 2013

* Doctor e Investigador en la Universidad Autónoma de Madrid. Correo electrónico: fabio. vlez@gmail.com 
E. R. Curtius, en Literatura europea y Edad Media latina, en el parágrafo $4^{\circ}$ del capítulo $2^{\circ}$ (titulados homónimamente: "Edad Media latina"), imprimía la siguiente observación: "La Biblia proporcionaba además al pensamiento histórico medieval una razón teológica para la idea de la sucesión de un reino por otro [...]. De la palabra transferre ('trasladar') se tomó el concepto de translatio, fundamental en la teoría medieval de la historia"'. Poco antes, y no era en vano, había aparecido una alusión a la Civitas Dei de San Agustín, en un contexto teológico relacionado con las profecías de Daniel. La translatio imperii, no obstante, sólo empezaría a tomar cuerpo y presencia tardíamente, en un intento por hacer revivir artificiosamente un caído Imperio romano. Era menester, pues, situarse en aquella profética Roma -el "cuarto y último imperio" (precedido por el de macedonios, persas y asirios)- que sobreviviría, póstuma e inexplicablemente, entre griegos, francos y germanos.

Ahora no se trata, por tanto, de volver a contar la Historia. Aquello de la transfiguración de las duae civitates en translatio imperii, las "llaves" y el ministerio de Pedro, el protagonismo esencial de personajes como Carlomagno o Constantino, o los intereses empeñados por la Iglesia y el Imperio ${ }^{2}$. No. Sino, más bien, de pensar -al decir de Curtius- la translatio y el Imperio como categorías estructurales de la Edad Media (y no sólo) ${ }^{3}$. Es por ello que, según creemos, no se podría desligar el Imperio de su condición de figura. Y decir que el Impero es figura, es decir también que es promesa, profecía, umbra futurorum. Así, que este no pueda cumplirse y consumarse, realizarse perfectamente, estaría ligado inexorablemente a una concepción onto-teo-lógica de la temporalidad cristiana (mundus senescens) $)^{4}$. Que no pueda hacerlo de suyo, es decir, que el Paraíso siempre quede fuera de la Historia, no impide que el Imperio pugne, por ayuda y designio divinos, hacia él. Digámoslo así: Babilonia no es, en efecto, la esperada Jerusalén, pero Roma nos indica que vamos por buen camino. Nos las habemos, pues, con una Historia sagrada. He aquí la translatio imperii.

Otra cosa muy distinta, según antes se insinuó, es cómo conjugar coheren-

${ }^{1}$ CurTius, E. R., Literatura europea y Edad Media latina (traducción de M. Frenk Alatorre y A. Alatorre, Madrid, F. C. E., reimpresión 1981, p. 52.

${ }^{2}$ Fundamentalmente, porque Pососк J. G. A. ya lo ha hecho de manera magistral en el tercer volumen de Barbarism and Religion, titulado The First Decline and Fall (Cambridge University Press, Cambridge, 2003). A este respecto, importante son los estudios de Goez, W., "Translatio Imperii" (Tübingen, Mohr, 1958); y de VAn Den BAAR, P. A., Die kircheliche Lehre der "Translatio Imperii romani" (Roma, Cura Pontificae Universitatis Gregorianae edita, 1956).

${ }^{3}$ De obligada referencia es Gierke, Otto von, Teorias politicas de la Edad Media (traducción P. García-Escudero sobre la edición de F. W. Maitland, Madrid, Centro de Estudios Políticos Constitucionales, 2010).

${ }^{4}$ Esta lectura tiene una profunda influencia en AuERBACH, E., Figura (traducción de Yolanda García y J. A. Pardos, con un excelente "Prólogo" de J. M. Cuesta Abad, Madrid, Trotta, 1998). Este texto, que se encuentra recopilado en los Gesammelte Aufsätze zur romanischen Philologie, debería leerse en conjunción con otro no tan conocido, Typological Symbolism in Medieval Literature (Bern, Francke, 1967), pp. 109-14. 
temente un "después de Roma” con la translatio y el Imperio5. Incluso toda escatología tiene su umbral de paciencia. Que se inventara, por ejemplo, una donatio retroactiva ${ }^{6}$, dice mucho al respecto. Mucho, efectivamente, porque revela ejemplarmente lo humano, demasiado humano del asunto. Pero igualmente, mucho, porque ello significaba que poco restaba ya de aquella Historia. La translatio imperii no dejaba de ser a este respecto un katéchon a la moderna y secular Historia nuestra ${ }^{7}$. Y ello implicaba, por de pronto, que lo que antes era imposible, porque no podía darse en este mundo, ahora lo era. No en vano, detrás de las monarquías y repúblicas posteriores, fruto de la escisión imperial, se dejaba ya traslucir una inminente renovatio. Pero no avancemos acontecimientos. La idea a pensar, después de todo, es la siguiente: si el Imperio no puede ser, ni ser apropiable, su translatio no puede dejar de ser o mero pleonasmo, o clara contradicción realizativa.

Pocos textos como el De monarchia de Dante permiten comprender la complejidad de un Imperio universal y su complemento, la translatio imperii. Y ello responde no sólo a la perspicaz apuesta conciliarista que allí se presenta, sino, antes bien, a la exposición crítica de un debate que, contaminado desde dos vertientes antagónicas, había ido sepultando interesadamente las múltiples aristas que conformaron este concepto clave del Medioevo. Y es que cuando Dante escribe -digámoslo así- el Imperio no es lo obvio ${ }^{8}$.

El De monarchia comienza presentándose sin disimulación, es decir, perfilando con firmeza tanto el objeto de análisis, como su método correspondiente. La

${ }^{5}$ Agradezco al profesor Antonio Valdecantos que me alertara de las posibles diferencias entre una translatio imperii extramuros y otra intramuros (es decir, "más allá" o "más acá" de Roma), desde una particular lectura: VEYNE, Paul, El imperio grecorromano (traducción de E. del Amo, Madrid, Akal, 2009), pp. 11-68.

${ }^{6}$ A este respecto, en clave jurídica, es muy recomendable de MAFFEI, Domenico, La donazione di Costantino nei giuristi medievali (2º reimpresión, Milano, Giuffrè, 1980.

${ }^{7}$ Sobre el katechon y el Imperio cristiano, véase de SchmiTt, Carl, El "nomos" de la Tierra (traducción de D. Schilling Thou, Granada, Comares, 2002), pp. 22 y ss.

${ }^{8}$ Como sagazmente ha apuntado Ullmann, W., Historia del pensamiento político en la Edad Media (traducción de Rosa Vilaró, Barcelona, Ariel, 2009), p. 180: "se trataba ante todo de un tratado [el De monarchia] que venía a cubrir una exigencia de su época y que presentaba todos los rasgos propios de un período en que lo nuevo aún no había aparecido del todo y lo antiguo tampoco había desaparecido del todo. Miraba hacia atrás, pero también hacia adelante". Un joven Kelsen, Hans, La teoría del Estado en Dante Alighieri (traducción de J. L. Requejo, Oviedo, KRK, 2007), p. 288, anotaba en una sintonía similar: "Sin embargo, el ideal de Estado de Dante no está en sintonía con el tiempo. Todavía no, porque en muchos puntos se anticipaba a su época; ya no, porque su fundamento, la base sobre la que se construía, el Imperio Universal, había agotado su tiempo". Recuérdese, a propósito del pasaje citado, aquel del Convivium (edición de F. Molina Castillo, Madrid, Cátedra, 2005), pp. 470-471: "De manera que, representando su autoridad con una imagen, se puede decir del Emperador que es como el jinete de la voluntad humana, siendo harto evidente que (¡especialmente en la pobre Italia, que ha quedado sin media alguno para su gobierno) ese caballo va por el campo sin jinete". Imagen, por cierto, que vuelve a aparecer en De monarchia, al final del libro III. 
tarea es, pues, investigar el significado "desconocido" del concepto "Monarquía temporal", también denominado "Imperio": "Primum quidem igitur videndum quid est quod' temporalis Monarchia' dicitur, typo ut dicam et secundum intentionem. Est ergo temporalis Monarchia, quam dicunt 'Imperium', unicus principatus et super omnes in tempore vel in hiis et super hiis que tempore mensurantur. Maxime autem de hac tria dubitata queruntur: primo nanque dubitatur et queritur an ad bene esse mundi necessaria sit, secundo an romanus populus de iure Monarche offitium sibi asciverit; et tertio an auctoritas Monarche dependeat a Deo inmediate vel ab alio, Dei ministro seu vicario"'.

De modo que la empresa comienza por distinguir un concepto, si bien, abordando e incluyendo tanto las características generales como su significado específico $^{10}$. Y la definición aventurada al inicio es clara y distinta: la monarquía temporal es "aquel único principado que se encuentra por encima del resto en el ámbito de lo temporal" ${ }^{11}$. Es decir, un tipo específico de "principiado de principados" que ostentaría como rasgo inherente y singular la supremacía última. Una vez presentada, Dante procederá a justificar -en esto consistirá toda la Monarchia- su necesaria y debida existencia desde tres planteamientos: a saber, si la monarquía es necesaria o no para el bien común (libro I), si Roma fue tal monarquía de iure o de facto (libro II) y si la autoridad del monarca depende directamente de Dios o de un tercero intermediario (libro III).

Dispuesta de esta guisa la arquitectura a recorrer, parecería que Dante pretende dar cuenta de la monarquía desde un abanico de frentes no necesariamente vinculados entre sí, aunque en todo caso, montados con un evidente rigor expositivo. $\mathrm{Y}$, sin embargo, para asombro de cualquier lector, cuando nos encontramos cerca del final del Libro segundo, desviándose aparentemente del pautado plan inicial, Dante aclara su verdadero interés en este tratado: "Et iam manifestum est quod romanus populus per duellum acquisivit Imperium: ergo de iure acquisivit; quod est principale propositum in libro presenti"12.

Y es precisamente este "derecho de duelo" (ius duelli) el eslabón que va a permitir vincular las tres cuestiones desligadas en el arranque. No es casual, por consiguiente, que el "derecho de duelo" sea el responsable de mostrar la imposibilidad efectiva de la "monarquía temporal" ideal y, en virtud de lo cual, la necesidad de una reconsideración de la translatio imperii; así como tampoco que el Libro tercero esté consagrado, casi en su totalidad, a repensar la translatio cuando no hay -porque no puede haber- de hecho imperio.

Pero sigamos el recorrido con concierto. Las primeras páginas del libro I están dedicadas a justificar una teleología cuyo fin último (ultimus finis), la paz

\footnotetext{
${ }^{9}$ Me he servido de dos ediciones: Dante, Monarchia (edición de P. Shaw, Firenze, Le Lettere, 2009a), p. 338 y (para las traducciones) DANTE, Monarquía (traducción de L. Robles y L. Frayle, 2a edición, Madrid, Tecnos, 2009b).

${ }^{10}$ Sobre esta forma de proceder ("tipo ut dicam et secundum intentionem") y su origen aristotélico, veáse la perspicaz exégesis de NARDI, B., Nel mondo di Dante (Roma, Edizione di Storia e Letteratura, 1944), pp. 93-6.

${ }^{11}$ Dante, Monarchia, cit. (n. 9, 2009b), p. 5.

${ }^{12}$ Dante, cit. (n. 9, 2009a), p. 397.
} 
universal, pudiera advenir con el asentamiento de la monarquía. Y el problema del monarca, así como su razón de ser, surge ciertamente ante la necesidad de amparar universalmente: "Et ubicunque potest esse litigium, ibi debet esse iudicium; aliter esset inperfectum sine proprio perfectivo: quod est impossibile, cum Deus et natura in necessariis non deficiat. Inter omnes duos principes, quorum alter alteri minime subiectus est, potest ese litigium vel culpa ipsorum vel etiam subditorum -quod de se patet-: ergo inter tales oportet esse iudicium. Et cum alter de altero cognoscere non possit ex quo alter alteri non subditur-nam par in parem non habet imperium-oportet esse tertium iurisdictionis amplioris qui ambitu sui iuris ambobus principetur. Et hic aut erit Monarcha aut non. Si sic, habetur propositum; si non, iterum habebit sibi coequalem extra ambitum sue iurisdictionis: tunc iterum necessarius erit tertius alius. Et sic aut erit processus in infinitum, quod esse non potest, aut oportebit devenire ad iudicem primum et summum, de cuius iudicio cuncta litigia dirimantur sive mediate sive inmediate: et hic erit Monarcha sive Imperator. Est igitur Monarchia necessaria mundo"13.

El monarca, como ya se indicó aunque someramente, se diferencia del príncipe en que se encuentra más allá de este, por encima suyo. Como juez supremo y último, en la medida en que entre príncipes no hay de iure predominio, su tarea está destinada a la resolución de litigios en virtud de su mayor potestad ("tertium iurisdictionis amplioris"). Por tanto, entre fuerzas que se presumen iguales, el objetivo es cerrar la previsible fisura, la diseminación imparable (processus in infnitum), ya que entre príncipes, sin instancia suprema a la que acudir, sólo cabría esperar el caos y la injusticia.

Para asegurar este orden universal se diseña precisamente la figura del monarca. Se espera de esta suerte que de su mayor poder (iustus potentior) se extienda tanto más la acción de la justicia (iustitia amplior). Pues, como afirma Dante, "justicia y poder se oponen" (“iustitia contrarietatem habet in posse"). De lo que se deriva que: "Ex hac itaque declaratione sic arguatur: iustitia potissima est in mundo quando volentissimo et potentissimo subiecto inest; huiusmodi solus Monarcha est: ergo soli Monarche insistens iustitia in mundo potissima est"14.

Se entiende de esta manera que, poco después, Dante distinga al monarca del príncipe en razón de la limitación (o no) de su potestad territorial: "Et hoc metu cupiditatis fieri oportet, de facili mentes hominum detorquentis. Ubi ergo non est quod possit optari, inpossibile est ibi cupiditatem esse: destructis enim obiectis, passiones esse non possunt. Sed Monarcha non habet quod possit optare: sua nanque iurisdictio terminator Occeano solum: quod non contingit principibus aliis, quorum principatus ad alios terminantur, ut puta regis Castelle ad illum qui regis Aragonum"15.

Ciertamente, no es lo mismo no tener límites que tenerlos; una cosa es verse rodeado de iguales, "como, por ejemplo, el reino de Castilla está limitado por el reino de Aragón” "16, que tener tan sólo como linde el océano. En definitiva, lo

\footnotetext{
${ }^{13}$ Ibíd. p. 349 (espaciado mío).

${ }^{14}$ Ibíd., p. 351(espaciado mío).

${ }^{15}$ Ibíd., p. 352.

${ }^{16}$ DANTE, cit. (n. 9, 2009b), p. 22.
} 
que distingue al monarca es que no tiene par, "no tiene enemigo" ${ }_{17}$ ("hostes habere non possit") y, en consecuencia, no puede desear ya nada, pues todo se halla en su seno. La ausencia de codicia, del beneficio propio, es la garantía de una recta dilectio, la justicia ${ }^{18}$.

Ahora bien, ¿y si el monarca no logra un poder absoluto? ¿Sería posible entonces una justicia universal (iurisdictio universalis)? $\mathrm{O}$ en el dudar de Dante: ¿Y si falta el juicio humano, bien por ignorancia, bien por carecer de la figura de un mismo juez ("vel propter presidium iudicis non habere")? Entonces, subraya, para que la justicia no sea abandonada, sería necesario recurrir a Dios. Y aquí es donde se introduce el "derecho de duelo". Es en la guerra, observando por supuesto los pertinentes requisitos formales, donde se cumple y se hace justicia atendiendo justamente a la "voluntad divina" (divine voluntatis) y a la "divina providencia" (divinam providentiam). En suma: "lo que se adquiere por duelo, se adquiere conforme a derecho"19 ("Et quod per duellum acquiritur, de iure acquiritur"). Es Dios quien suple, por tanto, las limitaciones efectivas del monarca. Al menos eso es lo que parece desprenderse de los últimos párrafos de la Monarchia: "Quod si ita est, solus eligit Deus, solus ipse confirmat, cum superiorem non habeat"20.

Pues bien, si esto es así, y Dios es el único que elige, significándose y confirmándose indirectamente por medio del "duelo", entonces, efectivamente, no tendría ni habría lugar para superior alguno ("superiorem non habeat"). Dios actuaría como juez último ante las limitaciones efectivas e históricas del monarca. De esta guisa, divina providencia y translatio imperii tramarían el curso de la Historia, y signos (signa) y milagros (miracula), recogidos entre poetas e historiadores, constituirían su ratio cognoscendi $i^{21}$.

${ }^{17}$ Ibíd., p. 24.

${ }^{18}$ No podemos sino compartir, con Truyol Serra, Dante Alighieri y el "imperium mundi" (Murcia, Publicaciones de la Universidad de Murcia, 1952-1953), p. 20, este escepticismo: «¿No pecará aquí Dante de un optimismo psicológico excesivo?”.

${ }^{19}$ DANTE, cit. (n. 9, 2009b), p. 71.

${ }^{20}$ DANTE, cit. (n. 9, 2009a), p. 436.

${ }^{21}$ Ibíd., pp. 390-3911 (espaciado mío): "Primus nanque in mortalibus, qui ad hoc bravium anelavit, Ninus fuit Assiriorum rex: qui quamvis cum consorte thori Semiramide per nonaginta et plures annos, ut Orosius refert, imperium mundi armis temptaverit et Asyam totam sibi subegerit, non tamen occidentales mundi partes eis unquam subiecte fuerunt [...]. Secundus Vesoges, rex Egipti, ad hoc bravium spiravit, et quamvis meridiem atque septentrionem in Asya exagitaverit, ut Orosius memorat, nunquam tamen dimidiam partem orbis obtinuit, quin ymo a Scithis inter quasi athlotetas et terminum ab incepto suo temerario est aversus. Deinde Cirus, rex Persarum, temptavit hoc: qui, Babilone destructa imperio que Babilonis ad Persas translato, nec adhuc partes occidentales expertus, sub Tamiride regina Scitharum vitam simul et intentionem deposuit. Post hos vero Xerxes, Darii filius et rex in Persis, cum tanta gentiam moltitudine mundum invasit, cum tanta potentia, ut transitum maris Asyam ab Europa dirimentisinter Sexton et Abidon ponte superaverit. Cuius operis admirabilis Lucanus in secundo Farsalie memor fuit; canit enim ibi sic: Talis fama canit tumidum super equora Xerxem construxisse vias. Et tandem, miserabiliter ab incepto repulsus, ad bravium pervenire non potuit. Preter istos et post, Alexander rex Macedo maxime omnium ad palmam Monarchie propinquans, dum per legatos ad deditionem Romanos premoneret, apud Egiptum ante Romanorum responsionem, ut Livius narrat, in medio quasi cursu collapsus est [...]. 'O altitudo divitiarum et scientie et sapientie Dei', quis hic te non obstupescere poterit? Nam conantem Alexandrum prepedire in cursu coathletam romanum tu, nesua temeritas prodiret ulterius, de certamine rapuisti. Sed quod 
A pesar del tratamiento ejemplar que se le da al Imperio romano de Augusto, es evidente que no puede tomarse como una realización y materialización completa de la "monarquía temporal". Con todo, la "pax romana" no era la "pax universalis". De ahí que, por poner un ejemplo, en el contexto de una alusión crítica al universalismo de la Iglesia, en el que Dante cuestionaba la posibilidad de que esta portase de facto la autoridad suprema y universal, se esgrimiera como prueba evidentísima (manifestissimis probationes) que hubiera partes de África, Asia y Europa que escaparan a su dominio ${ }^{22}$. Siguiendo una metáfora utilizada en el De Monarchia, a propósito de las diferencias entre el Imperio de Augusto y el de Constantino, podría aventurarse lo siguiente: que la "túnica inconsútil" (tunica inconsutilis) fuera desgarrada en la donatio ${ }^{23}$ efectuada por Constantino al papa Silvestre (y sus sucesores), no implica en ningún caso que el Imperio de Augusto fuese una "monarquía temporal”. Que la esencia de la túnica (léase: Imperio) comporte el que no pueda dividirse, no supone por su parte que tenga que ser absoluta. Lo que en todo caso la división en dos preludiaba era un cambio de rumbo. Pues como indica Dante: "dividir el Imperio equivaldría a destruirlo, ya que el imperio consiste en la unidad" ${ }^{24}$. Podría interpretarse, entonces, que la monarquía histórica de Augusto fue la que más estrechamente se asemejó a su ideal, a partir de la cual, dejaría de ser proyecto, para comenzar su declinar. En cualquier caso, la dependencia divina es la que va a constituir el punto de partida para la revisión de la translatio imperii: "Auctoritas principalis non est principis nisi ad usum, quia nullus princeps se ipsum auctorizare potest; recipere autem potest atque dimictere, sed alium creare non potest, quia creatio principis ex principe non dependet. Quod si ita est, manifestum est quod nullus princeps potest sibi substituere vicarium in omnibus equivalentem: qua re instantia nullam efficaciam habet"25.

Tras la táctica del ius duelli se constata que el príncipe no depende exclusivamente de su potestad porque no puede darse la autoridad a sí mismo ("nullus se ipsum auctorizare potest"); a lo sumo, y por delegación, puede hacer uso (usum)

Roma palmam tanti bravii sit adepta, multis comprobatur testimoniis [...]. Hoc etiam testimonium perhibet scriba Cristi Lucas, qui omnia vera dicit, in illa parte sui eloquii: "Exivit edictum a Cesare Augusto, ut describeretur universus orbis"; in quibus verbis universalem mundi iurisdictionem tunc Romanorum fuisse aperte intelligere possumus. Ex quibus omnibus manifestum est quod romanus populus cunctis athletizantibus pro imperio mundi prevaluit: ergo de divino iudicio prevaluit, et per consequens de divino iudicio obtinuit, quod est de iure obtinuisse",

${ }^{22}$ DanTe, cit. (n. 9, 2009b), p. 120.

${ }^{23}$ No puede detenerme ahora en la historia de la "Donatio Constantini", aunque supone un hito insorteable en la translatio imperii. Véase, en clave histórica, el libro de VIAN, Giovanni Maria, La donazione di Constantino (Bologna, Il Mulino, 2004). Respecto a la posición equívoca de Constantino en el ámbito religioso (paganismo vs cristianismo), remito a BURCKHARDT, J., Del paganismo al cristianismo. La época de Constantino el grande (versión de E. Imaz, México, F. C. E., 1945), en especial pp. 331-81. Clásico merecido por su trascendencia histórica y filológica es Valla, Lorenzo, De falso credita et ementita constantini donatione (edición bilingüe italiana de O. Pugliese, La falsa donazione di Constantino, Milano, BUR, 2007).

${ }^{24}$ Dante, cit. (n. 9, 2009b), p. 110. Sería de interés desde la etimología derivada de Agusto (augere), leer del Convivio, IV, VI. Por su cercanía, también, la Epistola VII.

${ }^{25}$ DANTE, cit. (n. 9, 2009a), p. 416. 
de ella tanto en cuanto la voluntad divina lo apruebe ${ }^{26}$. Lo cual, es otra forma de exponer que la "iurisdictio" antecede y somete al "iudice": "Preterea, omnis iurisdictio prior est suo iudice: iudex enim ad iurisdictionem ordinatur, et non e converso; sed Imperium est iurisdictio omnem temporalem iurisdictionem ambitu suo comprehendens: ergo ipsa est prior suo iudice, qui est Imperator, quia ad ipsam Imperator est ordinatus, et non e converso. Ex quo patet quod Imperator ipsam permutare non potest in quantum Imperator, cum ab ea recipiat esse quod est" 27.

Es, entonces, cuando Dante enuncia la imposibilidad intrínseca de una transferencia de poder, a saber, el hecho de que un vicario pudiese acaparar la suficiente autoridad como para dar y quitar el poder temporal y transferírselo a otro ("auctoritatem habet dandi et tollendi et etiam transferendi sceptrum regiminis temporalis”). Dante tenía en mente la donación de Constantino y, como hacía notar al comienzo del libro III, se estaba dirigiendo a aquellos que claramente pretendían hacer depender el Imperio de la Iglesia ${ }^{28}$. Desde ahí se desprendían las irreversibles conclusiones: "nadie puede dar [transferir] lo que no es suyo" 29 ("quia nemo potest dare quod suum non est"), "lo que no posee"30 ("Nichil est quod dare possit quod non habet"). El herético corolario se deja vislumbrar ya: ni la Iglesia hubiera podido recibir a título de propiedad, ni el Emperador conferir el título de enajenación ${ }^{31}$. Y si así hubiera sido, al dictar los Digesta, la transferencia sería claramente ilegítima, pues "la usurpación de derecho no crea derecho"32 ("usurpatio enim iuris non facit ius"). Es más, el propio Dante no desaprovechará semejante oportunidad para recordar sucesos históricos contrarios, como el del Emperador Otón, en los cuales fue el emperador -y no el Papa-quien se apropió indebidamente del derecho.

El usufructo del imperio, es decir, la no propiedad ni apropiabilidad del mismo, exigía, en el sentir de Dante, una reevaluación profunda de los supuestos actores. De ahí la aclaración: "Ex quo haberi potest ulterius quod nec isti qui nunc, nec alii cuiuscunque modi dicti fuerint 'electores', sic dicendi sunt: quin potius 'denuntiatores divine providentie' sunt habendi"33.

Estos -Papa y Emperador- debían ser relegados de su rango: habían pasado de un papel activo (capaces de elección y transferencia) a uno pasivo (meros anunciadores) ${ }^{34}$. La postura de Dante es coherente y, por ello, a la vez contun-

\footnotetext{
${ }^{26}$ Una objeción similar, secularizada la potestas imperii en la figura de la lex regia, podía encontrarse en gran parte de los "glosadores". Véase el breve pero iluminador artículo de MOREL, H., La place de la "lex regia” dans l histoire des idées politiques, en Etudes offertes à Jean Macqueron (Faculté de Droit et des Sciences Économiques d'Aix-en-Provence, 1970), pp. 545-55.

${ }^{27}$ DANTE, cit. (n. 9, 2009a), p. 424. Sobre este problema axial del Medioevo es inevitable la referencia a P. Costa, P., Iurisdictio. Semantica del potere politico nella pubblicistica medievale (1100-1433) (Milano, Giuffrè, reimpresión 2002).

${ }^{28}$ DANTE, cit. (n. 9, 2009b), p. 91.

${ }^{29}$ Ibíd., p. 100.

${ }^{30}$ Ibíd., p. 119.

${ }^{31}$ Ibíd., p. 111.

${ }^{32}$ Ibíd., p. 112.

${ }^{33}$ DANTE, cit. (n. 9, 2009a), p. 436.

${ }^{34}$ Un interesante estudio a la evolución que juegan estas dos instituciones en la obra de
} 
dente: quien transfiere no es el Papa, ni el Emperador, sino la voluntad divina por medio del "duelo" en la Historia. Mediante esta estratagema, Dante logró sacar del debate a los intermediarios partícipes a la sazón en la translatio imperii ${ }^{35}$. El poder y el imperio dependen ahora directamente ("sine ullo medio") de Dios (a Deo dependant $)^{36}$. De esta manera, se divinizaba la Historia y quedaba teologizada la política. Y, a pesar del perspicaz conciliarismo, Dante preparaba la independencia del Imperio ${ }^{37}$.

Luego ciertamente vendrían otros: Marsilio de Padua, Nicolas de Cusa, Guillermo de Ockham ${ }^{38}$ Pero la herencia había quedado ya grabada: hay translatio porque no hay Imperio de facto. En todo caso, promesa de imperio en traducción.

Como ya se hizo notar, el tiempo de Dante es un tiempo de transición en lo que a la validación del Imperio se refiere. Durante el siglo XVI y principios del siglo XVII, la monarquía española parecía, a consecuencia de una translatio más, portar el liderazgo del Imperio, entonces también denominado "monarchia universalis" 39 . Lo especial del caso no entraba en contradicción con lo obvio, esto es, la normalización del poder en la convivencia de distintos reinos ("rex imperator in regno suo, civitas sibi princeps"). Así y todo, que los reyes pretendiesen entonces serlo también fuera de su reino, más allá de sus fronteras reconocidas, debería hacernos repensar la supuesta modernidad derivada de un mutuo y pacífico ajuste entre estados soberanos ${ }^{40}$.

En Dante hemos visto revelarse una de las articulaciones más sutiles de la translatio imperii. Ahora trataremos de seguir desde otro contexto - precisamente no de

Dante, se ve en Passerin d'Entrèves, A., Dante as a Political Thinker (Oxford, Clarendon Press, 1965).

${ }^{35}$ Gilson en su excelente monográfico sobre Dante, sintetizaba genialmente esta idea: "En Dante, los órdenes de jurisdicción son sistemas cerrados, que sólo se juntan en Dios": GiLson, E., Dante y la filosofia (traducción de M. L. Mujica Rivas, EUNSA, Pamplona, 2004), p. 188. Sobre la supuesta influencia tomista y averroísta en el pensamiento de Dante, más allá de tópicos acríticos, véase las pp. 162 ss., 200 y ss., respectivamente.

${ }^{36}$ Véase: FigGIS, J. N., El derecho divino de los reyes (traducción de E. O’Gorman, F. C. E., México, reimpresión 1982), en especial, pp. 41-61.

${ }^{37}$ Véase las dos últimas páginas del De monarchia.

${ }^{38}$ No puedo demorarme en esta herencia, que bien me gustaría. Remito, no obstante, a SkInNER, Q., The Foundations of Modern Political Thought (Cambridge, Cambridge University Press, 1978), dos volkúmenes.

${ }^{39}$ Véase de Campanella, Tomas, La monarquía hispánica (1620, traducción de P. Mariño, Madrid, Centro de Estudios Constitucionales, 1982). Sobre la historia del concepto "Monarchia universalis", véase: BosвасH, Franz, "Monarchia Universalis". Ein politischer Leitbegriff der früheren Neuzeit (Göttingen, Vandenhoeck \& Ruprecht, 1988).

${ }^{40}$ Como ha destacado sagazmente Fernández-Albaladejo, Pablo, Fragmentos de monarquía (Madrid, Alianza Editorial, 1992), pp. 168-84: "Quiere ello decir que la idea imperial no dejó de estar presente como referente político en los últimos momentos de la baja edad media y principios de la moderna". A este respecto, es de obligado paso el detenerse en este genial artículo: 'Imperio de por si': la reformulación del poder universal en la temprana Edad Moderna". 
transición- el sostenimiento de una figura epigonal, y en parte anacrónica, como era el Imperio en los escritos de un jurista de la corte de Felipe II. Nos referimos a Vázquez de Menchaca y a sus Controversiae illustres (1564-1572). Si interesa esta lectura más que cualquier otra, ello se debe a que es aquí y ahora donde pueden identificarse los argumentos para la negación de una translatio imperii. Y, tal vez, la mejor forma de abordarlo sea desde los mismos cabos lanzados por Dante ${ }^{41}$.

Sorprende a primera lectura, si se lee desde el contrapunto del De monarchia, que, a diferencia de Dante, donde la contraposición de facto/de iure configuraba toda su estrategia, Vázquez de Menchaca insista desde el inicio en el valor de "lo notorio" para sus diversas conclusiones: "Siendo esto tan notorio que toda prueba sería inútil, bastando la sola alegación ya que lo notorio sobrepasa en veracidad y pronta compensación a toda prueba como se deduzca de varias leyes" ${ }^{\text {"2 }}$. De lo apuntado se desprende (como se constatará en el resto de Libros) que para Vázquez de Menchaca, en contraposición a Dante, sólo tiene sentido y valor lo puramente fáctico.

La premisa que Dante empleaba para negar la translatio a través de mediadores temporales -Papa o Emperador-venía a decir, más o menos, algo así: no se puede enajenar aquello que previamente nunca se tuvo. Y el Imperio era una propiedad que había sido usurpada bajo un aparente y mal entendido derecho. Vazquez de Menchaca, por su parte, apenas comenzado el libro 1, muestra estratégicamente un particular escepticismo respecto al derecho de propiedad, que bien merecería alguna atención. Escribe entonces: "Ni hace al caso el que quien disfruta de la posesión de un bien deba conservar aquella posesión mientras otro no pruebe competirle derecho sobre aquella cosa [...] pero no sucede ésto si la cosa es de tal naturaleza que no tiene duración o sucesiva perseverancia, porque entonces el derecho de posesión (si puede llamársele así y no con más justicia y propiedad sombra de derecho) terminaría en el primer acto y cada vez [...] y en cada acto parecería nacer y terminar, según la regla asimismo antes expuesta, sin que de tal acto reste o persevere ningún derecho para lo futuro" ${ }^{4}$.

Más que exponer propiamente lo esperable de un "derecho de posesión", Vázquez de Menchaca menciona la posibilidad, corrigiéndolo, de algo distinto, rebajado: una "sombra de derecho". Esto entronca con lo apuntado anteriormente a propósito de lo notorio y lo fáctico, y advierte nuevamente acerca del escaso papel de lo jurídico. Ciertamente, que un derecho -como el de propiedad- no perdure y se conserve a lo largo del tiempo, esto es, no sea mensurable desde un

${ }^{41}$ Esta acotación estratégica trae consigo, como es previsible, una panorámica incompleta del rico y complejo pensamiento de Vázquez de Menchaca. Sobre su originalidad y ruptura para con la tradición neo-tomista y franciscana, y sirviendo de precedente para planteamientos modernos como los de Grocio o Hobbes, véase el competente estudio de BRETT, A. S., Liberty, Right and Nature: Individual Rights in Later Scholastic Thought (1997, Cambridge, Cambridge University Press, 2003), en especial pp. 165-205.

${ }^{42}$ VÁZQUeZ de MENCHACA, F., Controversiarum illustrium aliarumque usu frequentium libri tres, libro I (ed. bilingüe de F. Rodríguez, Valladolid, Cuesta, 1931-1934), p. 17.

${ }^{43}$ Ibíd., p. 20. 
plano futuro, supone cuestionar de fondo, si no en su totalidad, tal derecho. Así procederá Vázquez de Menchaca:

Mas en el punto presente aunque ningún derecho se deriva para lo futuro, como queda demostrado, con todo aun concediendo y otorgando de grado que surgiera tal derecho, nada se seguiría aún contra nuestra causa, porque el derecho de posesión protege al poseedor, sólo mientras no se presente otro, que alegue más fuertes motivos y mejor derecho a ocupar aquel puesto. Este derecho no puede ser otro, según hemos visto, que el mayor poderío ${ }^{44}$.

Que sea la fuerza, el "mayor poderío", responsable de conceder y garantizar ocasionalmente un derecho dice, en efecto, muy poco de ese derecho. Y la argumentación prosigue: "lo más natural es que cada cosa cese al cesar el principio, única razón de su existencia” ${ }^{45}$. El derecho de propiedad es, por tanto, un derecho de poderío. Y no de un poder cualquiera, "en nuestro caso debe entenderse de un mayor poder actual, no pasado o desaparecido" ${ }^{46}$. Tras lo cual, como si nada tuviera que ver con ello y fuera un corolario necesario a la vez que accidental, Vázquez de Menchaca afirma:

Ahora bien, considerado el tiempo presente a nadie que no sea por completo ignorante, dejará de parecerle, no sólo cierto e indubitable, sino manifiesto y aun notorio (y como tal lo alegamos) el que el muy poderoso rey de las Españas aventaja en poder a todos los príncipes ${ }^{47}$.

Pasaje, que antecede a otro, donde tal derecho es presentado como el motor que explica la mudanza de imperios, pues ya "nada hay tan natural y frecuente como el que bajo la acción del tiempo, los reinos, los imperios, los poderíos todos y monarquías, crezcan y disminuyan, desaparezcan y vuelvan a nacer" ${ }^{38}$. Tan es así, es decir, importa tanto a Vázquez de Menchaca el remarcar que sólo interesa el "poder que actualmente está en pie" ${ }^{49}$, que llegará incluso a presentar la hipótesis de un poderío que habiendo perdido su supremacía y llegándola a recobrar con posterioridad, en nada tendría que ver o depender con la situación pasada. Habría que enjuiciarlo, antes bien, como un renacimiento, un nuevo y diverso poder. O traído de otro modo, en la Historia de Vázquez de Menchaca no habría siquiera lugar a las re-conquistas. De lo que puede deducirse, pues, que "sería absurdo y de una ignorancia crasa, el pretender deducir argumentos de tiempo y poderío pasados" 50 .

Hasta aquí hemos seguido el "derecho de poderío" desde lo temporal; toca ahora acercarse a él desde lo espacial. Dante, en el De monarchia, señalaba que los límites del Monarca se topaban con el océano, queriendo ilustrar con ello su ilimitación con respecto a los príncipes. La geografía de Vázquez de Manchaca es obviamente otra. De lo que podría deducirse que, consecuentemente, el Empera-

\footnotetext{
${ }^{44}$ Ibíd., p. 22.

${ }^{45}$ Ibíd.

${ }^{46}$ Ibíd., p. 30.

${ }^{47}$ Ibíd., p. 30.

${ }^{48}$ Ibíd.

${ }^{49}$ Ibíd., p. 42.

${ }^{50}$ Ibíd., p. 33.
} 
dor para serlo ahora, tendría que sobrepasar el mentado límite y adueñarse de lo restante $^{51}$. Pero, para sorpresa del lector, no puede ser el caso: "Porque habiendo sido dado, concedido o creado todo supremo poder de emperadores, reyes, príncipes, potestades y en una palabra, toda clase de supremo mando para exclusiva utilidad de ciudadanos y súbditos, y en modo alguno para la de los gobernantes; y como, si el poder de los emperadores romanos se extendiese al mundo entero, sería un régimen lleno de incomodidades, perjudicial y dañoso e imposible en extremo, es justo, razonable y consiguiente el que semejante imperio no extienda en modo alguno sus límites a todo el orbe. Sobre todo una vez descubierta por los españoles el Nuevo Mundo de las Indias situado en las regiones más apartadas, desconocidas y de difícil acceso [...] después de este descubrimiento, aparece en el día de hoy con mucha mayor claridad, ser en absoluto imposible, el que resida en manos de un solo hombre el dominio" 52 .

Por tanto, "tan dilatado imperio no puede corresponder de derecho a un solo hombre" ". Y ello no sólo porque "si atendemos al derecho de gentes, nadie ignora que jamás se ha admitido esa jurisdicción universal de un solo príncipe" ${ }^{54}$. Pues de esta manera, como aduce Vázque de Menchaca, sólo habría dos formas de hacerse con él: o por sumisión del resto a uno, acontecimiento aún por ver; o -desde el Derecho civil- por transferencia, lo cual es imposible porque nadie puede darse o dar un derecho universal sin que otro asimismo pueda hacerlo igualmente, "cosa digna de la mayor irrisión". Decíamos, pues, que se debía no sólo a los argumentos conforme a derecho anteriormente aludidos, sino, más bien, a la imposibilidad de que pudiera garantizarse de facto tal jurisdicción. Más si cabe, como se recordaba en la anterior cita, tras el descubrimiento del Nuevo mundo. Y concluye entonces: "como la potestad se otorgue sólo para ponerse en práctica, si no es posible el uso de esta potestad tan dilatada, siguese que semejante institución hubiera sido inútil" ${ }^{55}$.

Es así que Vázquez de Menchaca rectifica, retrocede y perfila: no se debe confundir -viene a decir- el "orbe" con el "mundo". La razón esgrimida, por su carga poética, merece ser recogida: “La palabra 'mundo' tiene varias significaciones; porque primeramente se toma del tocador de las mujeres, esto es por el adorno o compostura de las mismas, como aparece en numerosas leyes contenidas en los Digesta bajo el título de auro et argento legato; de tal significación se trasladó por

${ }^{51}$ Es conocido el debate jurídico que la navegación del océano suscitó entre los juristas europeos. Ciertos nombres, como Grocio, Pufendorf o Selden, bastarían para identificar los hitos más importantes. Lo que suele olvidar la Crítica es que todo ellos se vieron influidos, directa o indirectamente, por Vázquez de Menchaca (verbigracia, la importante mención de Grocio en el De iure belli ac pacis). Aunque la bibliografía a este respecto es muy numerosa, no en vano un "derecho universal" empezaba a tomar más que cuerpo, me gustaría citar un libro que trata, aunque a vuelo de pájaro, las diferentes concepciones que estos autores manejaban acerca de la propiedad. Me refiero a Tully, J., A Discourse on Property. John Locke and his Adversaries (Cambridge, Cambridge University Press, 1980), pp. 51-79.

${ }^{52}$ VÁzQuez de Menchaca, F., cit. (n. 42), libro II, pp. 24-5.

${ }^{53}$ Ibíd.

${ }^{54}$ Ibíd.

${ }^{55}$ Ibíd., p. 34. 
metáfora a designar la misma naturaleza (es decir el mundo) en razón del ornato tan bello que en él reina; y por tanto en dicho lugar con la palabra mundo sólo quiso designar el Emperador aquella parte de éste que por él era regida, llamándola así por hallarse más adornada que las restantes partes del mundo, esto es más culta y más libre de barbarie" 56 .

El emperador es el "señor del mundo". Y, casualidad o no, allí y entonces, "por este motivo nuestro muy poderoso rey señor D. Felipe se denomina señor del piélago o del ponto”.

Que un emperador del orbe sea fácticamente imposible no significa, sin embargo, que Vázquez de Menchaca no viese con buenos ojos la posibilidad y el beneficio de "un solo Señor supremo de todo el mundo": Es conveniente que exista en todo el orbe un Emperador, que sea señor y monarca de todo el mundo, para evitar que los reyes, príncipes o ciudadanos libres puedan aniquilarse impunemente unos a otros. Porque no es suficiente el que cada una de las naciones o provincias tenga su propio príncipe para tener a raya la audacia y perversidad de los ciudadanos ${ }^{57}$.

Tanto Dante como Vázquez de Menchaca montaron ambos edificios intelectuales desde un punto de partida común: el Imperio era fácticamente imposible. Pero donde el primero suplía esta limitación inyectando un télos divino a la Historia; el segundo, se conformaba en explicitar las consecuencias de semejante limitación material. De un lado hay derecho y duelo; del otro, facticidad y controversia. Otra forma de decir: translatio y conquista.

\section{BiBLIOGRAFÍA}

Curtius, E. R., Literatura europea y Edad Media latina (traducción de M. Frenk Alatorre y A. Alatorre, Madrid, F. C. E., reimpresión 1981).

\footnotetext{
${ }^{56}$ Ibíd., p. 29. Escribe a este respecto, con su perspicacia habitual: PAGDEN, A., Señores de todo el mundo. Ideologías del imperio en España, Inglaterra y Francia (en los siglos XVI, XVII y XVIII) (traducción de M. D. Gallart, Barcelona, Península, 1997), pp. 83-844.: "las Controversiae illustres a menudo tiene un tono, si no exactamente frívolo, sí impregnado de una gran ironía, que normalmente tiene como blanco a los neotomistas. Su alcance es, empero, mucho mayor del que pudiera parecer, pues, en la etimología de Vázquez, mundus pasa a definir no un dominio político, como habían dado por sentado muchos por falta de insuficientes conocimientos filológicos, sino cultural. Si bien Vázquez no acaba de precisar si sería legítimo exportar la belleza romana por la fuerza, no dejaba margen de duda de que ésta pudiera emplearse contra quienes amenazaran de un modo u otro dicha belleza. Al igual que un gran número de humanistas legales, de Alberico Gentile a Grocio, Vázquez aceptaba la postura de que lo único que podía justificar la guerra contra los bárbaros era que son "nuestros enemigos, perjudiciales, odiosos y peligrosos". La gran diferencia que separa nuestras costumbres de las suyas constituye una amenaza para nosotros. Su propia existencia es una amenaza para la belleza inherente del mundus que "nosotros" hemos creado",

${ }^{57}$ Ibíd., p. 55. Sobre este aspecto, véase de Carpintero Benitez, F., Del Derecho natural medieval al derecho natural moderno: Fernando Vázquez de Menchaca (Salamanca, Universidad de Salamanca, 1977), pp. 242 ss.
} 
Pocock, J. G. A., Barbarism and Religion (Cambridge University Press, Cambridge, 2003).

Goez, W., "Translatio Imperii" (Tübingen, Mohr, 1958).

Den BaAR, P. A., Die kircheliche Lehre der Translatio Imperii romani (Roma, Cura Pontificae Universitatis Gregorianae edita, 1956).

Gierke, Otto von, Teorías políticas de la Edad Media (traducción P. García-Escudero sobre la edición de F. W. Maitland, Madrid, Centro de Estudios Políticos Constitucionales, 2010).

Auerbach, E., Figura (traducción de Yolanda García y J. A. Pardos, con un excelente "Prólogo" de J. M. Cuesta Abad, Madrid, Trotta, 1998).

Auerbach, E., Gesammelte Aufsätze zur romanischen Philologie (Bern, Francke, 1967).

VeYne, Paul, El imperio grecorromano (traducción de E. del Amo, Madrid, Akal, 2009).

MAFFEI, Domenico, La donazione di Costantino nei giuristi medievali ( $2^{\circ}$ reimpresión, Milano, Giuffrè, 1980.

Schmitт, Carl, El "nomos" de la Tierra (traducción de D. Schilling Thou, Granada, Comares, 2002).

Ullmann, W., Historia del pensamiento político en la Edad Media (traducción de Rosa Vilaró, Barcelona, Ariel, 2009).

Kelsen, Hans, La teoría del Estado en Dante Alighieri (traducción de J. L. Requejo, Oviedo, KRK, 2007).

Dante, Convivium (edición de F. Molina Castillo, Madrid, Cátedra, 2005).

Dante, Monarchia (edición de P. Shaw, Firenze, Le Lettere, 2009a).

Dante, Monarquía (traducción de L. Robles y L. Frayle, 2a edición, Madrid, Tecnos, 2009b).

NARDI, B., Nel mondo di Dante (Roma, Edizione di Storia e Letteratura, 1944).

Truyol Serra, Dante Alighieri y el "imperium mundi" (Murcia, Publicaciones de la Universidad de Murcia, 1952-1953).

VIAN, Giovanni Maria, La donazione di Constantino (Bologna, Il Mulino, 2004).

Burckhardt, J., Del paganismo al cristianismo. La época de Constantino el grande (versión de E. Imaz, México, F. C. E., 1945).

Valla, Lorenzo, De falso credita et ementita constantini donatione (edición bilingüe italiana de O. Pugliese, La falsa donazione di Constantino, Milano, BUR, 2007).

Morel, H., La place de la "lex regia" dans l histoire des idées politiques, en Études offertes à Jean Macqueron (Faculté de Droit et des Sciences Économiques d'Aixen-Provence, 1970).

Costa, P., "Iurisdictio". Semantica del potere politico nella pubblicistica medievale (11001433) (Milano, Giuffrè, reimpresión 2002).

Passerin D'Entrèves, A., Dante as a Political Thinker (Oxford, Clarendon Press, 1965).

Gilson, E., Dante y la Filosofía (traducción de M. L. Mujica Rivas, Eunsa, Pamplona, 2004).

FIGGIS, J. N., El derecho divino de los reyes (traducción de E. O’Gorman, F. C. E., México, reimpresión 1982).

SkInner, Q., The Foundations of Modern Political Thought (Cambridge, Cambridge University Press, 1978), dos volúmenes. 
Campanella, Tomas, La monarquia hispánica (1620, traducción de P. Mariño, Madrid, Centro de Estudios Constitucionales, 1982).

BosBaCH, Franz, "Monarchia Universalis". Ein politischer Leitbegriff der früheren Neuzeit (Göttingen, Vandenhoeck \& Ruprecht, 1988).

Fernández-Albaladejo, Pablo, Fragmentos de monarquía (Madrid, Alianza Editorial, 1992).

BRETT, A. S., Liberty, Right and Nature: Individual Rights in Later Scholastic Thought (1997, Cambridge, Cambridge University Press, 2003).

VÁzQuez de Menchaca, F., Controversiarum illustrium aliarumque usu frequentium libri tres (ed. bilingüe de F. Rodríguez, Valladolid, Cuesta, 1931-1934).

Tully, J., A Discourse on Property. John Locke and his adversaries (Cambridge, Cambridge University Press, 1980).

Pagden, A., Señores de todo el mundo. Ideologias del imperio en España, Inglaterra y Francia (en los siglos XVI, XVII y XVIII) (traducción de M. D. Gallart, Barcelona, Península, 1997).

Carpintero Benitez, F., Del Derecho natural medieval al derecho natural moderno: Fernando Vázquez de Menchaca (Salamanca, Universidad de Salamanca, 1977). 
